Note

\title{
Standard Infrared Absorption Spectrum of Betaine and Optimal Conditions for its Measurement
}

(Received May 15, 2006)

\author{
Youji Kitamura *1, Toshinobu Iwasaki*2, Madoka Saito*2, Masaki Mifune*1, ${ }^{\dagger}$, \\ Yutaka Saito*1, Kyoko Sato*3, Chikako Yomota*3 and Kenichi TAnamoto*3 \\ $\left({ }^{* 1}\right.$ Department of Pharmaceutical Sciences, Graduate School of Medicine, Dentistry and \\ Pharmaceutical Sciences, Okayama University: Tsushima-Naka, Okayama 700-8530, Japan; \\ *2Department of Pharmaceutical Chemistry, Graduate School of Natural Science and Technology, \\ Okayama University: Tsushima-Naka, Okayama 700-8530, Japan; \\ *3National Institute of Health Sciences, Kamiyoga: Setagaya-ku, Tokyo 158-8501, Japan; \\ ${ }^{\dagger}$ Corresponding author)
}

\begin{abstract}
The infrared absorption (IR) spectrum is often used as a standard reference in identification tests of food additives in Japan. In the case of betaine, many different IR spectra have been reported and, therefore, it is necessary to establish an IR spectrum that is reproducible and reliable enough to be used as a standard for identification. In the present study, suitable conditions to obtain a standard IR spectrum were examined from various viewpoints, including pretreatment, selection of method, and measuring technique. The KBr disk method, which has generally been used to identify betaine, was found to be humidity-dependent, and there was also an interaction between betaine and $\mathrm{KBr}$. A reproducible IR spectrum suitable as a standard could be obtained by drying betaine at $105^{\circ} \mathrm{C}$ for 3 hours over phosphorus pentoxide, and then measuring the IR spectrum by the liquid paraffin (Nujol) paste method.
\end{abstract}

Key words: betaine; seasoning; infrared spectrum; reference spectrum; anhydride; hydrate; identification

\section{Introduction}

Betaine (Fig. 1) occurs widely in nature, especially in beets, and is used as a food additive for seasoning or as a flavor-improving agent in Japan. An identificationtest for betaine is described in "Voluntary Specifications of Existing Food Additives: 3rd Ed"1), which suggests identification of betaine on the basis of the wave numbers of the absorption bands in an infrared absorption (IR) spectrum measured by the KBr method, as well as retention time in HPLC, and the like. However, the criteria for identification employed in the test are not comprehensive; for example, the defined wave numbers do not include that of the absorption band of the $\mathrm{COO}^{-}$ group, which is one of the characteristic bands of betaine.

Apart from their use as food additives, betaine and related compounds have attracted much interest in terms of the relationship between IR spectra and struc-<smiles>C[N+](C)(C)CC(=O)[O-]</smiles>

Fig. 1. Structure of betaine ture, specifically, the influence of hydrogen bonding ${ }^{2)-5)}$. IR spectra of betaine are available from databases, for example, "The Sigma Library of FT-IR Spectra"6), "Spectral Database for Organic Compounds, SDBS"*1 of the National Institute of Advanced Industrial Science and Technology, Japan (AIST), and "WebBook" $* 2$ of the National Institute of Standards and Technology, USA (NIST). However, these IR spectra are very different from each other and hardly appear to represent the same compound.

In this study, we examined the influence of pretreatment, measuring method, and measurement conditions on the IR spectrum of betaine in order to establish a method to obtain a reliable and reproducible IR spectrum of betaine, to serve as a standard for an identification test.

\section{Materials and Methods}

\section{Samples and reagents}

Betaines (products of Nippon Beet Sugar Manufacturing Co., Ltd., and Danisco Japan Co., Ltd. Tokyo, Japan)

\footnotetext{
*1 http://www.aist.go.jp/RIODB/SDBS/cgi-bin/direct_frame top.cgi

*2 http://webbook. nist.gov / cgi / cbook.cgi? ID = C590476 \& Units $=$ SI\&Mask $=80$
} 


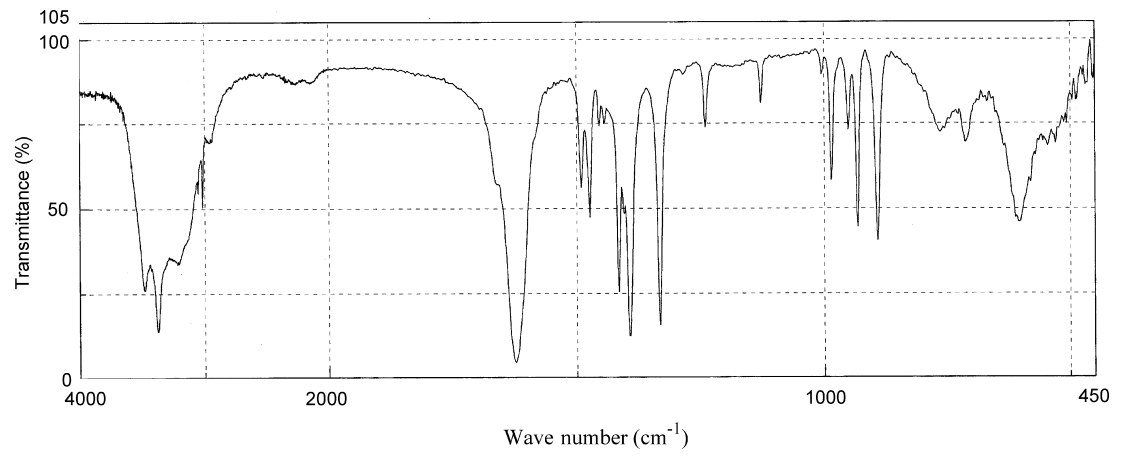

Fig. 2. IR spectrum of betaine dried over phosphorus pentoxide at $105^{\circ} \mathrm{C}$ for 3 hours (the $\mathrm{KBr}$ method)

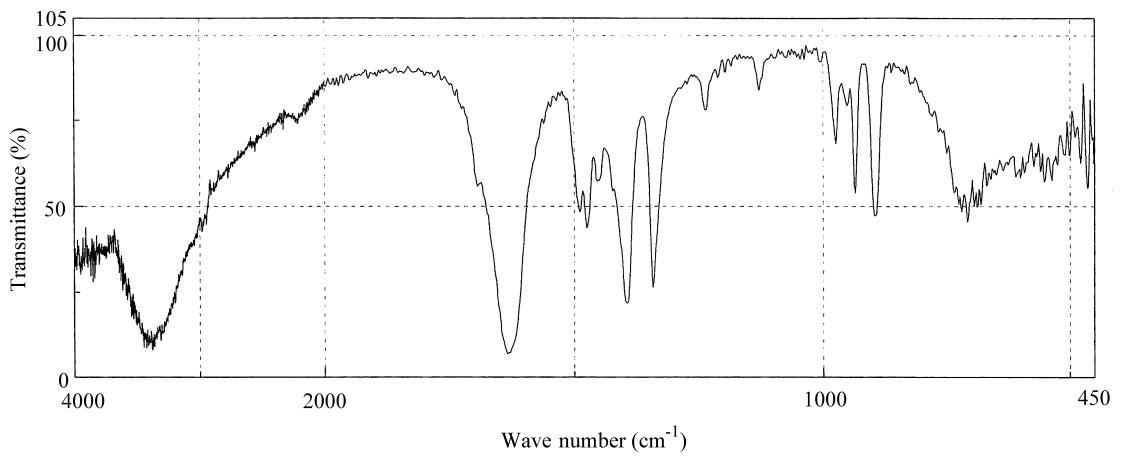

Fig. 3. IR spectrum of betaine dried over phosphorus pentoxide at $105^{\circ} \mathrm{C}$ for 3 hours (the $\mathrm{KCl}$ method)

were provided by Japan Food Additives Association (Tokyo, Japan) and used as received. Both betaines were in the form of white crystalline powders.

Liquid paraffin $\left(\mathrm{Nujol}^{\circledR}\right)$ and potassium bromide (KBr) for IR spectroscopy were purchased from Merck AG. (Germany) and JASCO Co., Ltd. (Hachiouji, Japan), respectively. Potassium chloride $(\mathrm{KCl})$ for IR spectroscopy was from JASCO Co., Ltd. (Japan).

\section{Measurements of IR spectra}

Measurements were carried out by the KBr method and the paste method using liquid paraffin as described in the 7th Ed. of Japan's Specifications and Standards for Food Additives ${ }^{7)}$ for measuring a solid sample. A $\mathrm{KBr}$ disk without any sample and a $\mathrm{KBr}$ optical plate were used as references in the $\mathrm{KBr}$ method and the paste method, respectively. The resolution was about 4 $\mathrm{cm}^{-1}$ (32 or 64 scans). The Fourier transform (FT)-IR device used was an Impact 400 FT-infrared spectrophotometer (Nicolet Co., Madison, Wis., USA) which could nominally measure up to $400 \mathrm{~cm}^{-1}$, though the practical limit was about $450 \mathrm{~cm}^{-1}$. The measurement was conducted in a room used exclusively for IR spectral measurement, where the humidity and temperature were controlled to $30-40 \%$ and $23^{\circ} \mathrm{C}$, respectively. $\mathrm{KBr}$ disks and pastes were usually prepared in the controlled room, but sometimes in an ordinary laboratory. Measurements using the $\mathrm{KCl}$ disk or paste method were carried out under the same conditions.
3. Recommended procedure for measurement of a standard IR spectrum of betaine

Betaine as a sample was dried over phosphorus pentoxide at $105^{\circ} \mathrm{C}$ for 3 hours. The IR spectrum was measured by using the paste method as described in the General Methods of the 7th Ed. of Japan's Specifications and Standards for Food Additives ${ }^{7}$. As a reference, a $\mathrm{KBr}$ optical plate was used.

\section{Results and Discussion}

\section{Examination by the disk method}

In the measurement by the $\mathrm{KBr}$ disk method, commercial betaine was used after having been dried at $105^{\circ} \mathrm{C}$ for 3 hours according to the "Loss on Drying Test" in the Voluntary Specifications of Existing Food Additives: 3rd Ed. ${ }^{1)}$ The dried betaine was first subjected to measurement by the $\mathrm{KBr}$ method according to the General Methods of the 7th Ed. of Japan's Specifications and Standards for Food Additives ${ }^{7}$. The IR spectrum obtained is shown in Fig. 2. The IR spectrum agreed well with that described in SDBS, but differed from those described in The Sigma Library (the paste method), NIST (the paste method) and reference 2 cited above (the $\mathrm{KBr}$ method), suggesting the importance of moisture absorption during disk preparation or an interaction between betaine and $\mathrm{KBr}$. To examine whether or not an interaction between betaine and $\mathrm{KBr}$ exists, a betaine disk was prepared using $\mathrm{KCl}$, and the IR spectrum was measured. The result is shown in Fig. 3. It is clear from Figs. 2 and 3 that the spectrum of betaine in the $\mathrm{KBr}$ disk is quite different from that in the $\mathrm{KCl}$ disk throughout the entire region measured. 


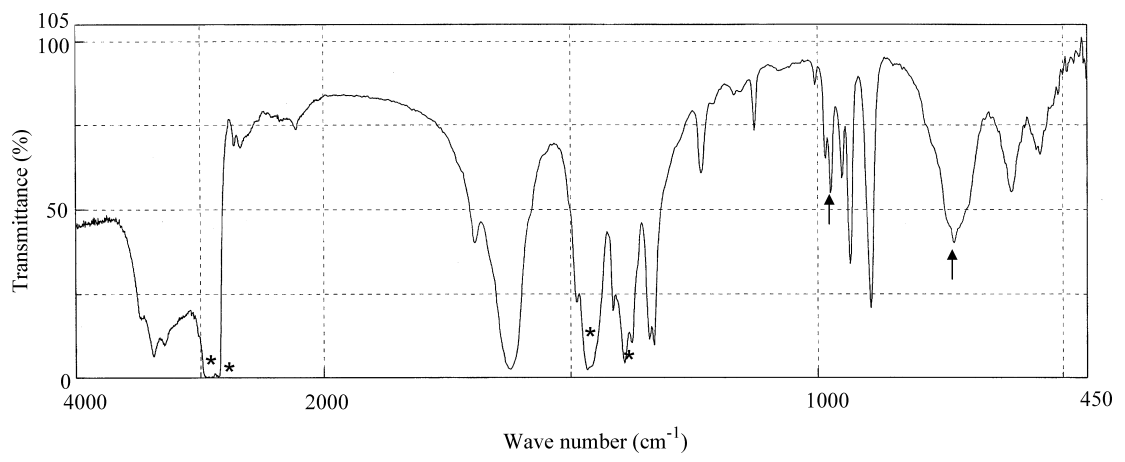

Fig. 4. IR spectrum of a 1:10 mixture of dried betaine and $\mathrm{KBr}$ (the paste method) *Bands due to liquid paraffin.

$\uparrow$ extra bands observed by the paste method.

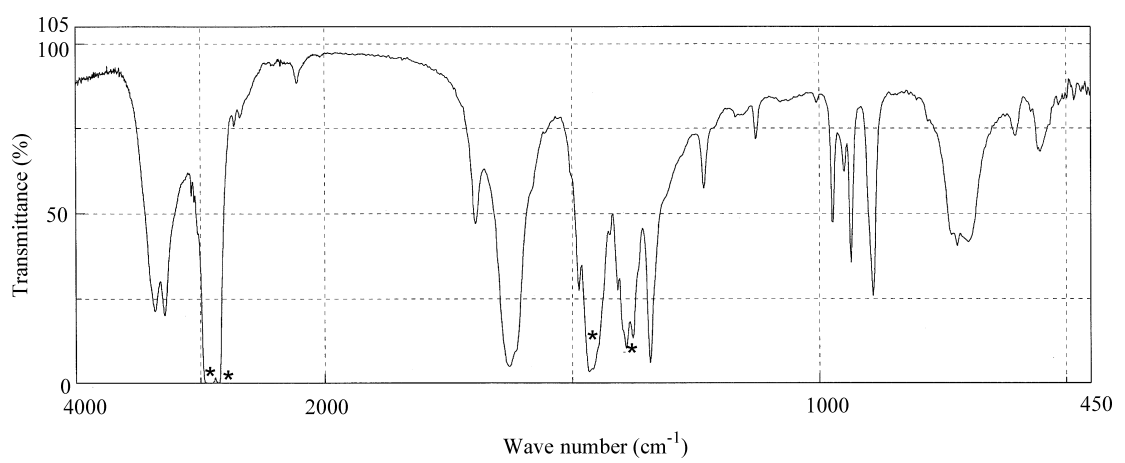

Fig. 5. IR spectrum of a 1:10 mixture of dried betaine and $\mathrm{KCl}$ (the paste method) *Bands due to liquid paraffin.

Thus, there was an interaction between betaine and $\mathrm{KBr}$ during the procedures of mixing and grinding, or compressing, which resulted in a change of the IR spectrum. In the $\mathrm{KBr}$ method, it is well known that a sample may form a solid complex with $\mathrm{KBr}^{8}$, or may interact with $\mathrm{KBr}$ through hydrogen bonding or ion-exchange ${ }^{9), 10)}$. To elucidate the causes of the altered spectrum, the IR spectrum of betaine was measured by the paste method using a paste prepared by mixing betaine and alkali metal halide $(\mathrm{KBr}$ or $\mathrm{KCl})$ at the mixing ratio of about $1: 10$ (betaine:alkali metal halide), and grinding in agate mortar. The measurement was carried out using a portion of the resultant paste, with a greater thickness than usual. The results are shown in Figs. 4 and 5.

The IR spectrum measured by the paste method in the presence of $\mathrm{KBr}$ (Fig. 4) and that of the $\mathrm{KBr}$ method (Fig. 2) are in good agreement in the region between 3,500 and $3,000 \mathrm{~cm}^{-1}$, and almost in agreement in the region of $1,000-800 \mathrm{~cm}^{-1}$ although extra bands (marked with $\uparrow$ ) exist. From these results, it was presumed that the spectrum of betaine is easily changed even by very mixing and grinding betaine with $\mathrm{KBr}$. When the $\mathrm{KBr}$ disk was prepared by very brief grinding, the IR spectrum of betaine was again different from that shown in Fig. 2.

It has been reported that the spectrum of betaine measured by the $\mathrm{KBr}$ method is influenced by the relative humidity in the measuring room ${ }^{2}$. It has also been reported that the IR spectrum of betaine anhydride, which was obtained by crystallization from ethanol, coincided with that of betaine hydrate when measurement was conducted by the $\mathrm{KBr}$ method under the condition of $12 \%$ or higher relative humidity ${ }^{2)}$. We measured the IR spectrum at a humidity level as low as possible $\left(23^{\circ} \mathrm{C}\right.$, relative humidity $\left.30 \%\right)$, but could not obtain the IR spectrum of betaine anhydride. The relative humidity varies greatly within Japan, and also among the cold districts (Hokkaido, North Europe, etc.) where betaine is mainly produced. Such regional differences in humidity may be linked to the variations observed in the IR spectra provided by the manufacturers in different districts, since test laboratories are not necessarily environmentally controlled. It was therefore considered that the $\mathrm{KBr}$ method does not necessarily give an IR spectrum with good reproducibility.

On the other hand, the IR spectrum measured by the paste method in the presence of $\mathrm{KCl}$ (Fig. 5) is in agreement with that measured by the $\mathrm{KCl}$ disk method (Fig. 3 ) in the region between 1,000 and $800 \mathrm{~cm}^{-1}$. In addition, these IR spectra are almost in agreement with the IR spectrum of betaine hydrate measured by the paste method described below, and, also are similar to the IR spectrum provided by NIST. These facts indicate that the $\mathrm{KCl}$ method is preferable, and that betaine tends to absorb moisture to form a hydrate. Therefore, further investigation into the IR spectrum was conducted by the paste method, which was hardly affected by humidity. 


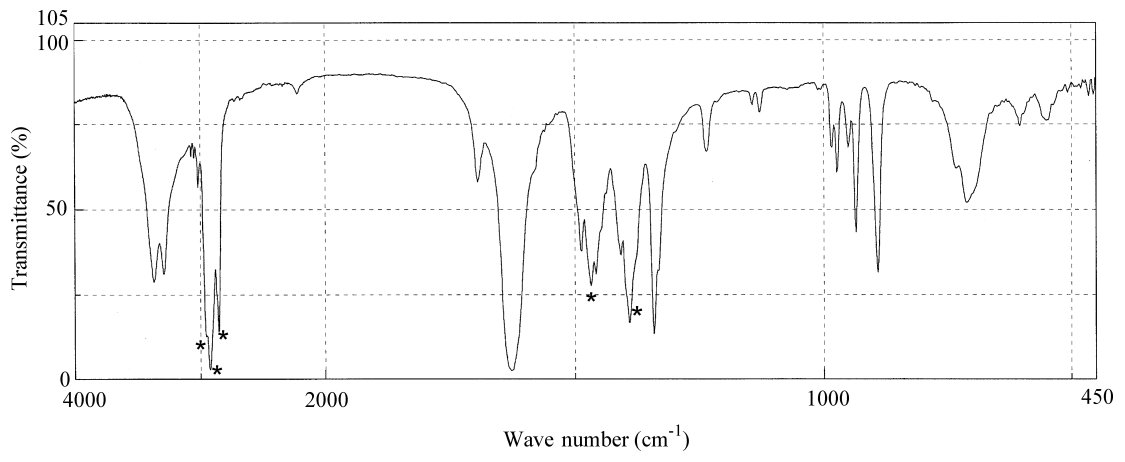

Fig. 6. IR spectrum of commercial betaine (the paste method) *Bands due to liquid paraffin.

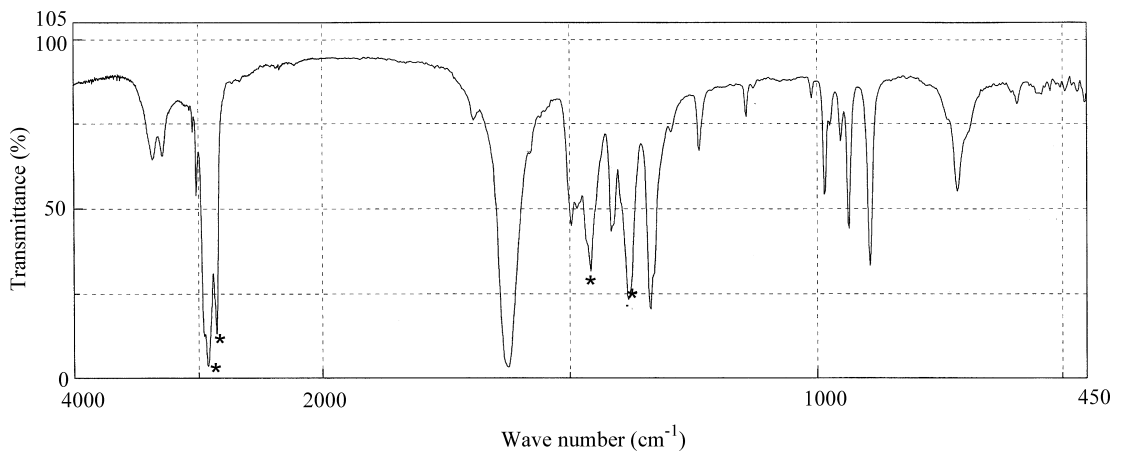

Fig. 7. IR spectrum of betaine dried over phosphorus pentoxide at $105^{\circ} \mathrm{C}$ for 3 hours (the paste method) *Bands due to liquid paraffin.

\section{Examination by the paste method}

In the paste method, a target substance is coated with liquid paraffin when preparing a paste for measurement. Therefore, the IR spectrum should be littel affected by humidity, even if the substance is hygroscopic. Figure 6 shows the IR spectrum of a betaine product (commercially available bulk powder) measured by the paste method without drying treatment. The high similarity of the IR spectrum in Fig. 6 to that of betaine hydrate in The Sigma Library ${ }^{6)}$ indicates that the bulk powder contained predominantly hydrate. Because the water content generally varies from one betaine product to another, the IR spectrum of a single product cannot serve as a standard IR spectrum. Another bulk powder also gave a similar IR spectrum to that shown in Fig. 6.

We then examined suitable drying conditions for obtaining the anhydride in a reproducible manner. Drying commercial betaine at $105^{\circ} \mathrm{C}$ for 3 hours did not affect the IR spectrum according to the General Method of "Loss on Drying Test" in the Voluntary Specifications of Existing Food Additives: 3rd Ed.' ${ }^{1}$ Thus, drying was conducted over phosphorus pentoxide at $105^{\circ} \mathrm{C}$ for 3 hours. The IR spectrum of this dried betaine is shown in Fig. 7. The IR spectrum in Fig. 7 agreed with that of betaine anhydride provided by The Sigma Library ${ }^{6}$. Further, the spectrum in Fig. 7 was in agreement with that of betaine anhydride measured by the $\mathrm{KBr}$ method $^{2)}$, except that the former also contains absorption bands due to liquid paraffin.

When drying was conducted at different tempera- tures, $120,140,170$ or $200^{\circ} \mathrm{C}$, over phosphorus pentoxide for three hours, the IR spectra of the dried betaine samples were identical. We, therefore, concluded that the IR spectrum shown in Fig. 7 could be available as a standard IR spectrum. Needless to say, when this spectrum is used as a standard in the identification of a betaine product, the spectra must be compared in the region other than that containing the absorption bands marked by "*”, which are due to liquid paraffin.

As mentioned above, the IR spectra of betaine hydrate measured by the $\mathrm{KBr}$ and paste methods were different. On the other hand, the IR spectrum of betaine anhydride measured by the $\mathrm{KBr}$ disk method at low humidity (relative humidity; less than 12\%) (2) $^{2}$ was in agreement with that of betaine anhydride measured by the paste method. Accordingly, when using the IR spectrum measured by the $\mathrm{KBr}$ method in the identification test of betaine, it is necessary to confirm that the spectrum is identical to the spectrum measured by the paste method in order to ensure the reliability of the test results. The identification method based on the IR spectrum has various advantages, including energy saving, and wide applicability, and is a convenient alternative to chemical identification methods. It is therefore important to ensure good reproducibility of the spectrum.

\section{Conclusion}

We examined suitable conditions and methods to obtain a reliable and reproducible IR spectrum applica- 
ble to identification of betaine as a standard spectrum. It was found that a reproducible spectrum can be obtained by drying betaine at $105^{\circ} \mathrm{C}$ for 3 hours over phosphorus pentoxide and then measuring the IR spectrum by the paste method. The IR spectrum thus obtained is suitable to be used as a standard reference IR spectrum.

\section{Acknowledgments}

This work was supported by a Grant-in-Aid for Scientific Research from the Ministry of Health, Labour and Welfare of the Japanese Government. We thank Associate General Manager M. Karasawa (Ajinomoto Co., Inc.) for his advice. We also thank Japan Food Additives Association, Nippon Beet Sugar Manufacturing Co., Ltd. and Danisco Japan Co., Ltd. for providing betaines.

\section{References}

1) Japan Food Additives Association Ed. "Voluntary Specifications of Existing Food Additives: 3rd Ed.", Japan Food Additives Association, Tokyo, Japan (2002).

2) Viertorinne, M., Valkkonen, J., Pitkanen, I., Mäthlouthi, M., Nurmi, J., Crystal and molecular structure of anhydrous betaine, $\left(\mathrm{CH}_{3}\right)_{3} \mathrm{NCH}_{2} \mathrm{CO}_{2}$. J. Mol. Struct., 477, 2329 (1999).

3) Toccalino, P. L., Harmon, K. M., Harmon, J., Hydrogen bonding: Part 26. Thermodynamics of dissociation and infrared spectra-crystal structure correlations for betaine monohydrate and trimethylamine oxide dehydrate.
J. Mol. Struct., 189, 373-382 (1988).

4) Dega-Szafran, Z., Jakólski, M., Szafran, M., OHO hydrogen bond and electrostatic interactions in a complex of pyridine betaine with phenylacetic acid studied by X-ray diffraction, FTIR spectroscopy and PM3, DFT calculations. J. Mol. Struct., 555, 191-201 (2000).

5) Baran, J., Barnes, A.J., Engelen, B., Panthöfer, M., Pietraszko, A., Ratajczak, H., Sledz, M., Structure and polarised IR and Raman spectra of the solid complex betainetrichloroacetic acid. J. Mol. Struct., 550-551, 21-41 (2000).

6) Keller, R. J., "The Sigma Library of FT-IR Spectra 1st Ed.", Sigma Chemical Co., Inc. (1986).

7) Ministry of Health, Labour and Welfare Ed. of "7th Ed. Japan's Specifications and Standards for Food Additives" published by The Ministry of Health and Welfare of Japanese Government (1999). This book can also be viewed at http://www.ffcr.or.jp/zaidan/FFCRHOME. nsf/pages/spec.stand.fa

8) Ketelaar, J. A. A., Hass, C., van der Elsken, J., Infrared absorption spectra of bifluorides in alkali halide disks. The formation of mixed crystals. J. Chem. Phys., 24, 624627 (1956).

9) Pliskin, W.A., Eischens, R.P., Effect of using the pressed salt technique to obtain the spectrum of chemisorbed ammonia. J. Phys. Chem., 59, 1,156-1,159 (1955).

10) Famer, V. C., Effects of grinding during the preparation of alkali-halide disks on the infra-red spectra of hydroxylic compounds. Spectrochim. Acta, 8, 374-389 (1957), see also Text Book for the IR spectroscopy, for example Jikken-Kagaku-Kouza Zoku Vol.10 "Infrared Spectra" in Japanese, Maruzen, Tokyo (1964). 